\title{
Aplikasi Pengunci Alamat Website dan Desktop di Perpustakaan Online Badan Pusat Statistik Provinsi Jawa Barat
}

\author{
Asep Sutisna \\ Badan Pusat Statistik Provinsi Jawa Barat \\ email : asepsutisna@bps.go.id
}

\begin{abstract}
ABSTRAK.Aplikasi pengunci alamat website dan desktop yang telah dirancang saat ini dapat diterapkan pada komputerkomputer layanan perpustakaan berbasis website(online) yang ada di Pelayanan Statistik Terpadu (PST) Badan Pusat Statistik (BPS) ProvinsiJawa Barat yang masih menggunakan web browser tanpa aplikasi pengaman.Kekurangan dari penggunaan komputer yang menggunakan web browser untuk alamat website yang telah ditentukan yaitu perpustakaan online BPS adalah rentan terhadap pengguna yang sering membuka alamat website selain yang telah ditentukan tersebut, merubah seting komputer yang telah ditentukan, dan membuka file-file yang tidak dijinkan.Hal ini karena petugas perpustakaan tidak dapat mengawasi secara langsung pengguna yang menggunakan komputer tersebut. Oleh karena itu aplikasi ini dirancang agar komputer yang digunakan untuk perpustakaan onlinedapat tidak dengan mudah diubah setingnya, pengguna tidak dapat membuka alamat website selain perpustakaan online, dan pengguna tidak dapat membuka file-file yang tidak dijinkan.Rancang sistem yang digunakan pada jurnal penelitian ini menggunakan metode low fidelity prototype. Hasil pengujian dengan metode black box menunjukkan bahwa pengguna komputer perpustakaan online hanya dapat membuka aplikasi perpustakaan online BPS dan seting komputer dapat terjaga setingannya dengan baik.
\end{abstract}

Kata Kunci: aplikasi windows; webkit; prototype

ABSTRACT.The application for locking the website address and desktop that have been designed at this time can be applied to library computers based on website services (online) in the Integrated Statistics Services (PST) of Statistics (BPS) of Jawa Barat which still uses a web browser without a security application. The disadvantage of using a computer that uses a web browser for a specified website address is that the BPS online library is vulnerable to users who often open a website address other than those that have been specified, change the specified computer settings, and open files that are not allowed. This is because library officers cannot directly monitor users who use the computers. Therefore this application is built so that the computers used for online library can not be easily changed, the user cannot open a website address other than an online library, and the user cannot open files that are not allowed. The system design used in this research journal uses the low fidelity prototype method. The results of testing with the black box method indicate that online library computer users can only open BPS online library application and computer settings can be maintained properly.

Keywords: website address locker; desktop locker

\section{PENDAHULUAN}

Teknologi informasi dan komunikasi atau ICT (Information and Communication Technology) telah menjadi bagian yang tidak terpisahkan dari kehidupan global.Oleh karena itu, setiap institusi, berlomba untuk mengintegrasikan ICT guna membangun dan memberdayakan sumber daya manusia berbasis pengetahuan agar dapat bersaing dalam era global.(Februariyanti \& Zuliarso, 2012).

Salah satu pemanfaatan ICT dapat diimplementasikan pada perpustakaan milik instansi pemerintah.Perkembangan mutakhir adalah munculnya perpustakaan digital (digital library) yang memiliki keunggulan dalam kecepatan pengaksesan karena berorientasi ke data digital dan media jaringan komputer (internet).(Supriyanto \& Muhsin, 2008).

Salah satu instansi pemerintah yang telah menggunakan sistem perpustakaan digital berbasis web adalah Badan Pusat Statitsik (BPS) Provinsi Jawa Barat. (BPS, 2018). Pada perpustakaan tersebut disediakan beberapa komputer berbasis MS Windows dan web browser untuk membuka halaman website perpustakaan online BPS.

Semakin banyaknya pengunjung perpustakaan BPS Provinsi Jawa Barat yang menggunakan komputer perpustakaan online dan semakin beragamnya tipe-tipe pengunjungtersebut,dimana salah satunya tidak mengikuti ketentuan dalam menggunakan komputer perpustakaan, menuntut BPS Provinsi Jawa Barat untuk membuat sebuah sistem untuk meminimalkan hal tersebut. 
Penulisan jurnal ini bertujuan untuk membuat sebuah sistem pengaman komputer perpustakaan dengan metode prototyping, dimana pengembangan software dititikberatkan pada pendekatan aspek desain, fungsi dan user-interface.Pengembang dan pengguna fokus pada user-interface dan bersama-sama mendefinisikan spesifikasi, fungsi, desain dan bagaimana software bekerja. Pengembang dan pengguna bertemu dan melakukan komunikasi dan menentukan tujuan umum, kebutuhan yang diketahui dan gambaran bagian-bagian yang akan dibutuhkan.(Yazdi, 2012).Selanjutnya desain antarmuka dilakukan dalam bentuk rancangan low-fidelity prototyping.

\section{METODE}

Metode yang digunakan adalah metode prototype yang sifatnya low fidelity prototype, dimana tidak terlalu rinci dalam menggambarkan sistem, mempunyai fungsi atau interaksi yang terbatas, dan menggambarkan konsep pendekatan secara umum. Tahapanprototypeini meliputi identifikasi kebutuhan, perancangan sistem, pengujian sistem, dan implementasi.

\subsection{Identifikasi Kebutuhan}

Identifikasi dilakukan untuk mengetahui keberadaan sistem yang sedang berjalan saat ini berdasarkan kebutuhan pengelola, kebiasaan pengguna, dan keberadaan perangkat pendukung yang digunakan.Berdasarkan identifikasi tersebut diketahui bahwa kebiasaan pengguna untuk membuka website selain website perpustakaan online relatif banyak.Selain itu kebiasaan pengguna yang membuka aplikasi selain yang diijinkan relatif banyak pula.Hal tersebut mengakibatkan komputer perpustakaan menjadi sering tidak berfungsi sebagaimana mestinya.Mengingat petugas perpustakaan yang relatif sedikit, dimana tidak mungkin selalu memeriksa pengguna komputer perpustakaan, maka diperlukan sebuah sistem aplikasi yang dapat mencegah hal-hal yang telah disebutkan di atas.Keberadaan sistem yang sedang berjalan saat ini dan sistem yang diusulkan terlihat pada gambar 1 dan gambar 2.

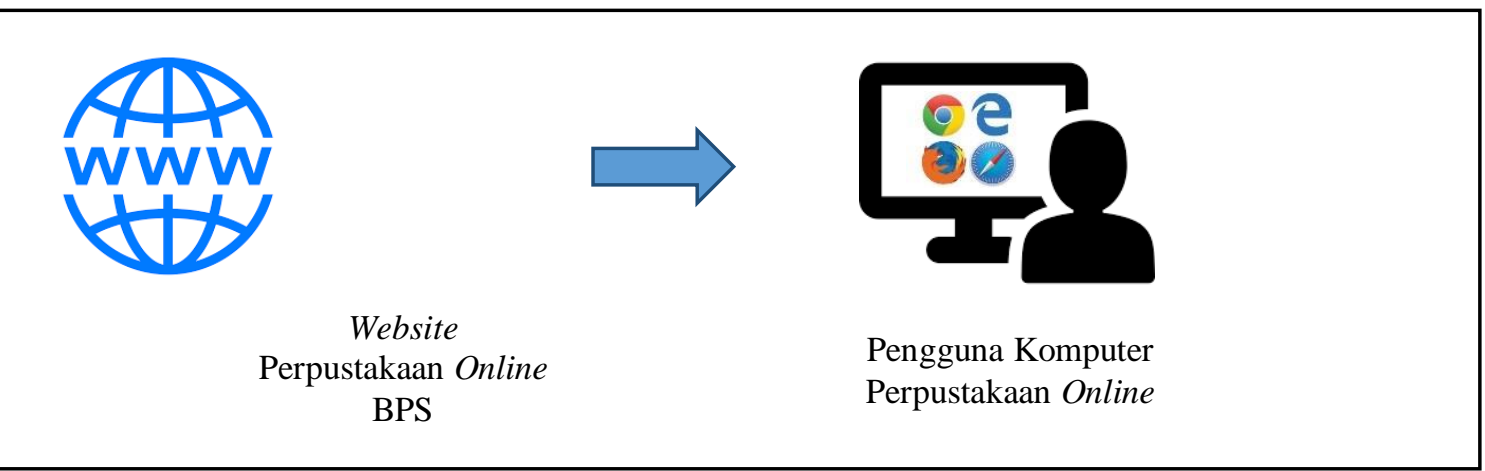

Gambar 1. Sistem yang sedang berjalan

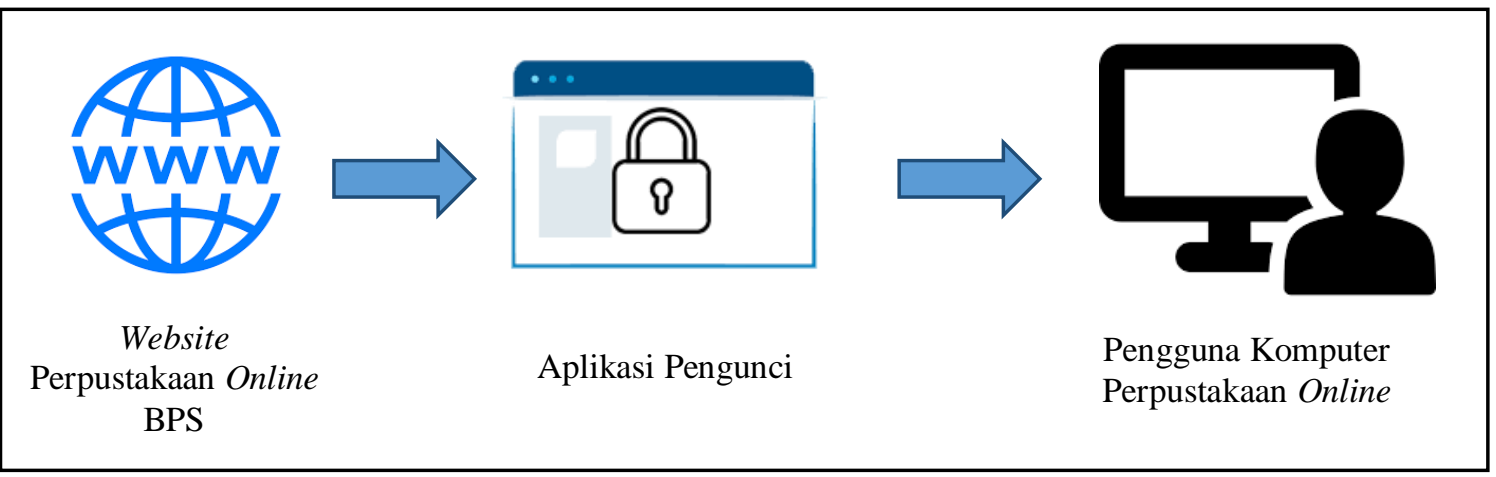

Gambar 2. Sistem yang diusulkan

\subsection{Desain Sistem}

Perancangan dan pembuatan prototype sistem dilakukan pada tahap ini, dimana prototype yang dibuat disesuaikan dengan kebutuhan sistem yang telah didefinisikan berdasarkan kebutuhan pengelola sistem perpustakaan. Perbedaan antara sistem yang sedang berjalan dengan sistem baru ini adalah adanya fungsi 62 
pada sistem untuk mengunci halaman website sesuai dengan yang ditentukan dan fungsi untuk mengunci desktop yang bermanfaat untuk mencegah pengguna untuk merubah pengaturan komputer dan menggunakan aplikasi lain selain perpustakaan online BPS. Flowchart (bagan alir) digunakan untuk menggambarkan alur logika dalam program yang dibangun.

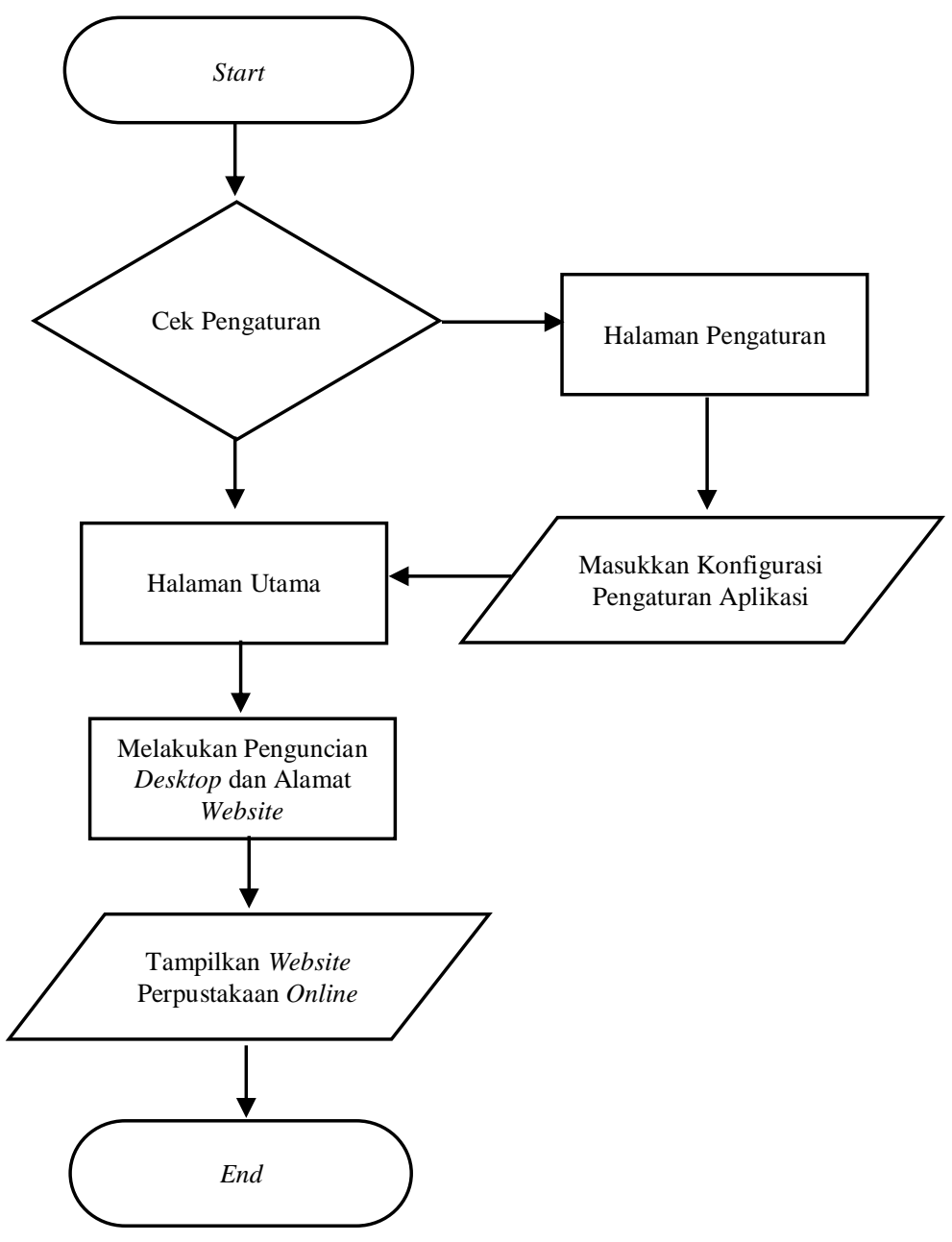

Gambar 3. Flowchart menampilkan halaman website perpustakaan

Flowchart yang ditampilkan di atas merupakan alur dari sistem yang diusulkan untuk melakukan penguncian halaman website dan desktop.Penjelasan dari diagram flowchart di atas adalah sebagai berikut:

1. Pertama,sistem akan mengecek apakah pengaturan aplikasi telah dilakukan. Jika sudah dilakukan maka halaman utama akan ditampilkan. Jika belum maka pengguna harus melakukan pengaturan aplikasi melalui halaman pengaturan.

2. Jika pengaturan telah dilakukan maka halaman websiteakan ditampilkan pada halaman utama. Pengguna dapat melakukan navigasi halaman pada website tersebut.

Untuk dapat menutup aplikasi, diagram flowchart di bawah ini menggambarkan posesnya. 


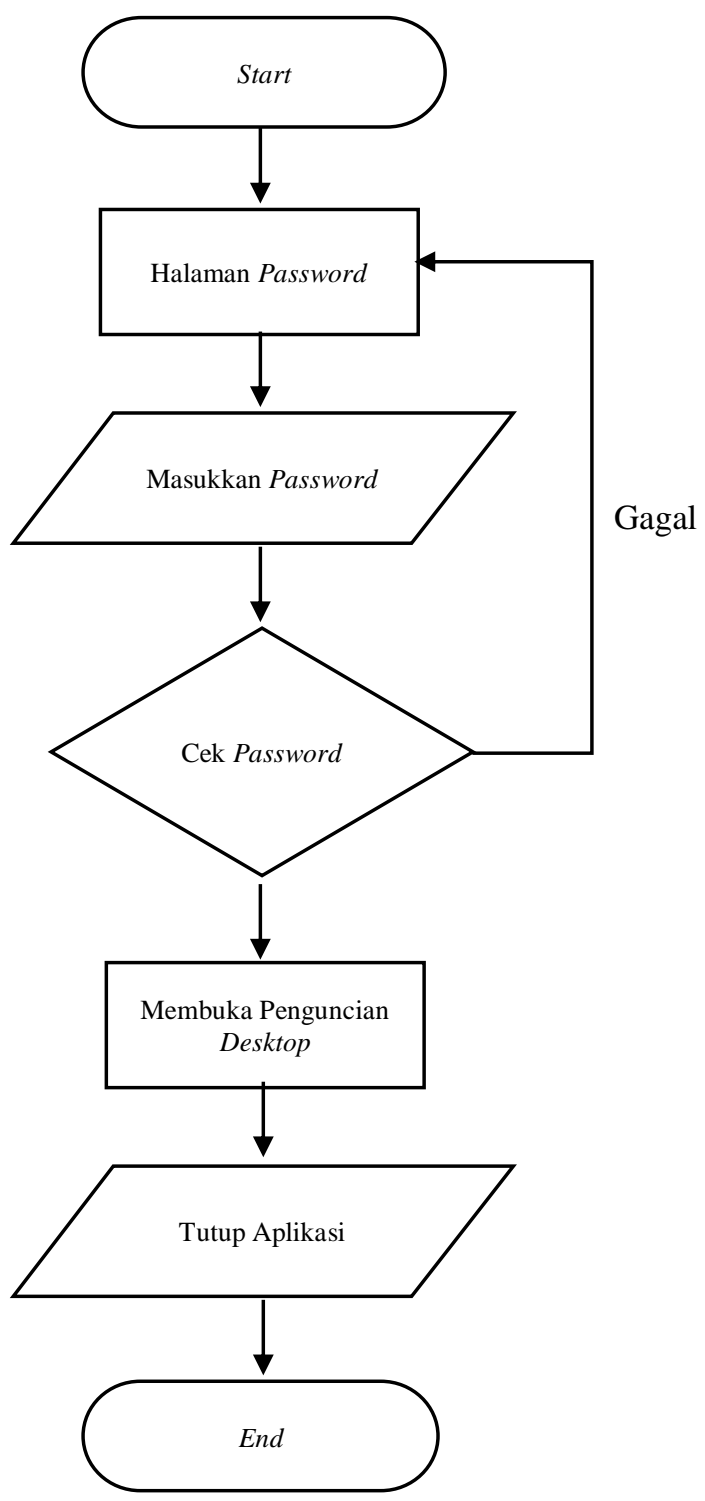

Gambar 4. Flowchart keluar aplikasi

Flowchart yang ditampilkan di atas merupakan alur dari sistem yang diusulkan untuk keluar dari aplikasi.Penjelasan dari diagram flowchart di atas adalah sebagai berikut:

1. Pertama,ketika pengguna hendakmenutup aplikasi maka akan ditampilkan form password.

2. Jika password yang dimasukkan sesuai maka sistem akan membuka penguncian desktop yang sebelumnya terkunci oleh aplikasi lalu aplikasi akan tertutup.

\section{HASIL DAN PEMBAHASAN}

Agar komputer yang digunakan untuk perpustakaan online tidak dengan mudah diubah setingnya, pengguna tidak dapat membuka alamat website selain perpustakaan online, dan pengguna tidak dapat membuka file-file yang tidak dijinkan, maka dirancanglah aplikasi pengunci alamat website dan desktop dengan menggunakan metode prototype.

\subsection{Form Pengaturan}

Pengaturan aplikasi dilakukan pada form pengaturan ini yang meliputi judulaplikasi, alamat website yang akan ditampilkan, dan pengaturan lainnya termasuk password untuk menutup aplikasi. 


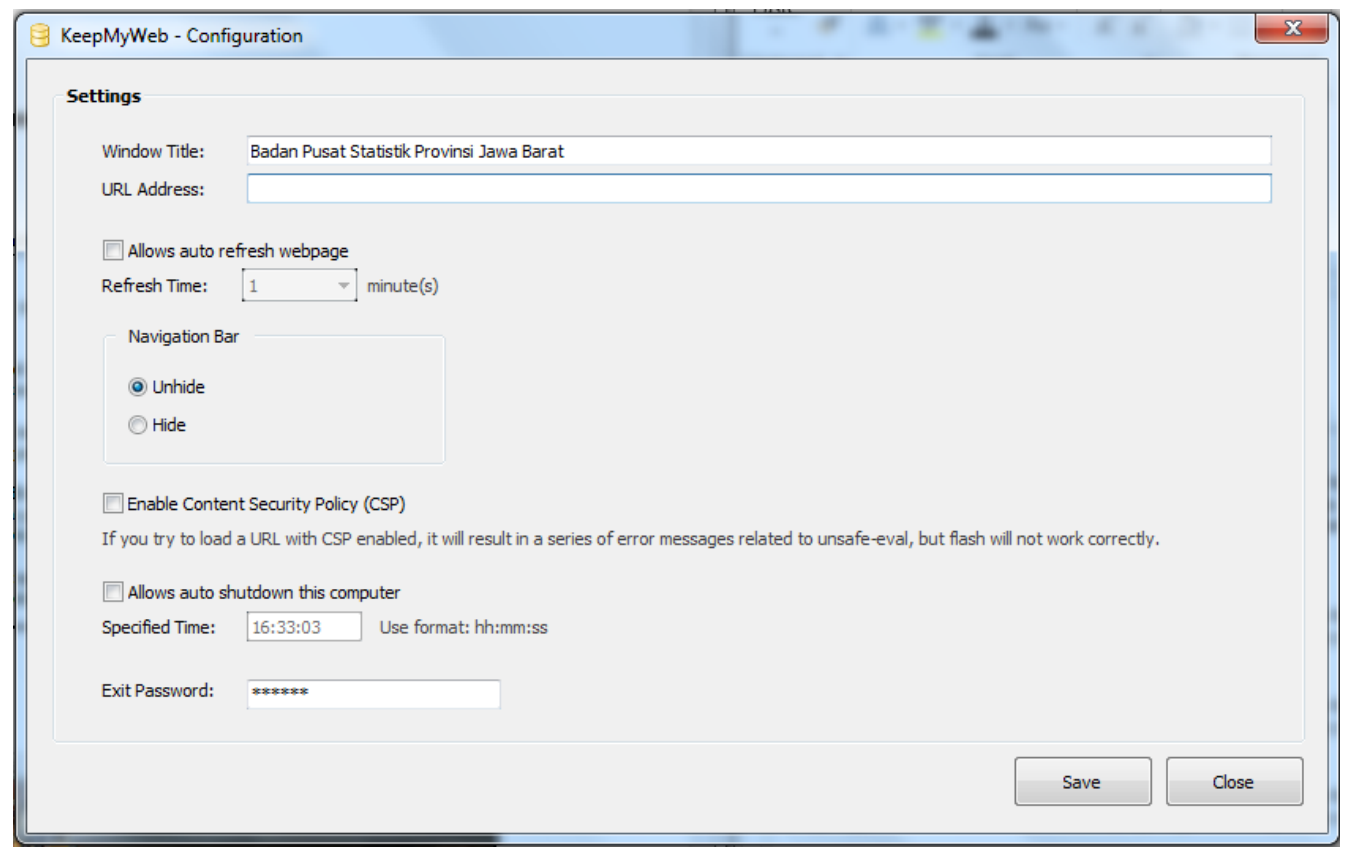

Gambar 5. Form Pengaturan

Pengaturan ini akan disimpan dalam sebuah file dimana sebelumnya dilakukan enkripsi agar isi file pengaturan tidak mudah dibaca. Isi file pengaturan ditunjukkan pada gambar 6 .

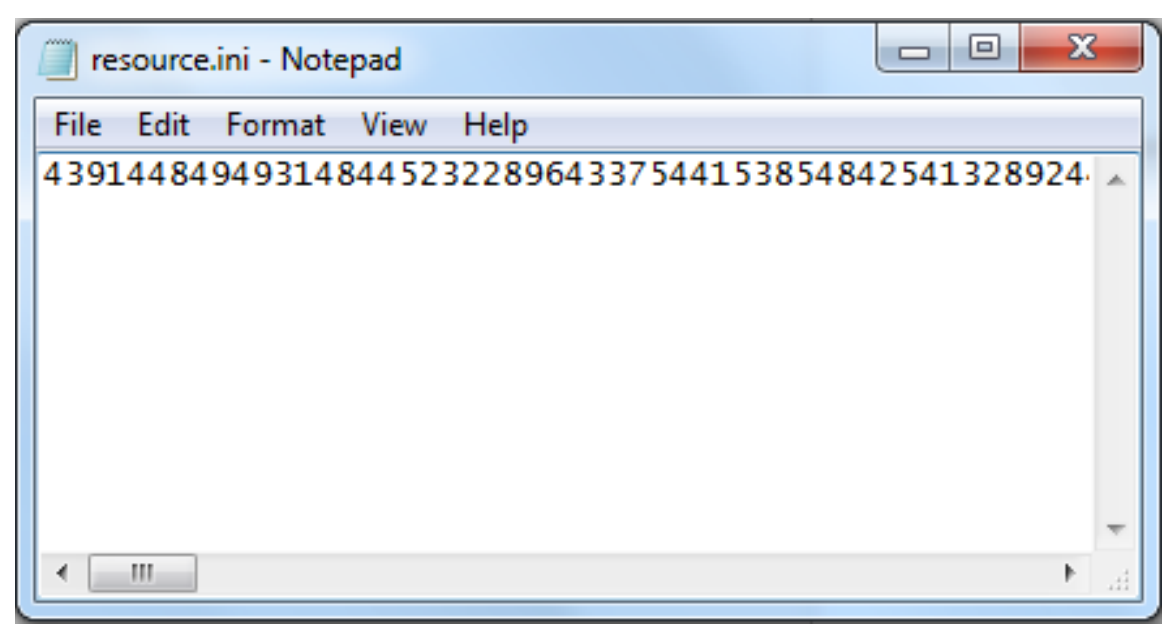

Gambar 6. File Penyimpanan Pengaturan

\subsection{Form Utama}

Form ini merupakan penampil utama dari aplikasi. Pada form ini akan ditampilkan halaman website dengan alamat perpustakaan online BPS yang telah ditentukan pada form pengaturan.Form ini akan mengunci tampilan desktop danmenonaktifkan fungsi-fungsi umum MS Windows seperti tombol Start Windows, kombinasi tombol keyboard Ctrl+Alt+Del, dan Task Manager.Form utama ditunjukkan pada gambar 7. 


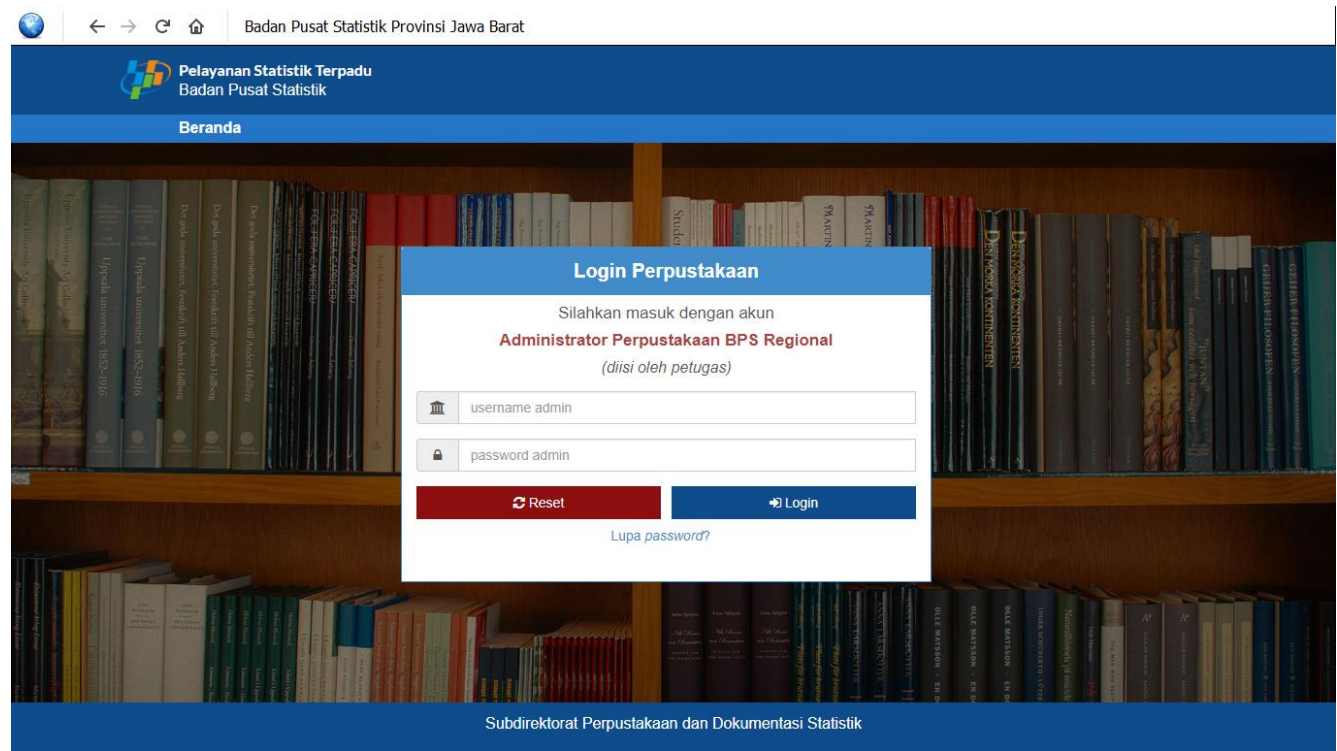

Gambar 7. Form Utama

Halaman website yang ditampilkan tidak menggunakan web browser yang umumnya dipasang pada MS Windows melainkan menggunakan sebuah engine bernama webkit(Webkit, 2018) yang terpasang pada aplikasi, sehingga aplikasi ini berfungsi juga sebagai web browser.

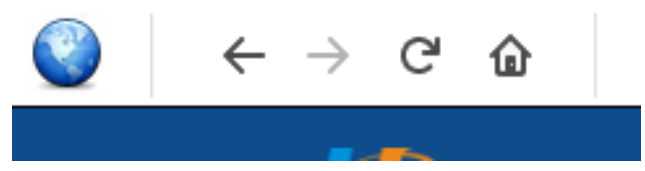

Gambar 8. Tombol-tombol navigasi

Mengingat aplikasi ini menampilkan halaman website, maka tombol-tombol yang biasa digunakan untuk navigasi halaman website dipasang pada aplikasi ini.Tombol-tombol navigasi ditunjukkan pada gambar 8 .

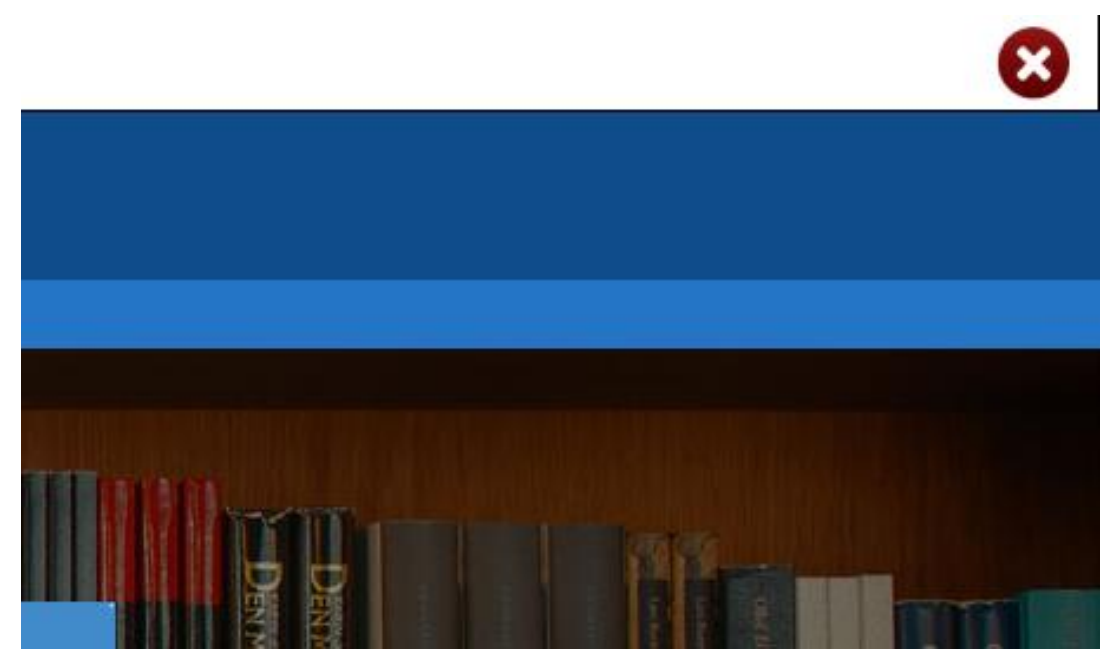

Gambar 9. Tombol Keluar 


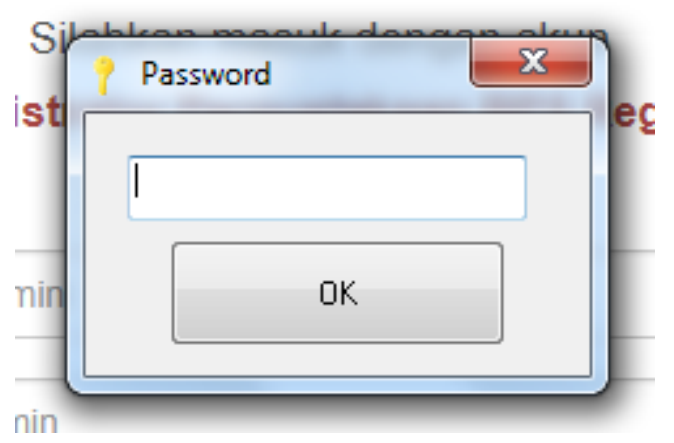

Gambar 10. Form Password

Untuk menghindari pengguna menutup aplikasi ini, maka dipasang tombol keluar yang ditunjukkan pada gambar 9,dimana jika diklik akan muncul formpassword yang ditunjukkan pada gambar 10. Password yang digunakan telah ditentukan pada form pengaturan. Jika password tersebut sesuai maka aplikasi akan tertutup dan semua fungsi MS Windows akan diaktifkan kembali. Tombol keluar akan terlihat jika kursor mouse digeser ke bagian kanan atas aplikasi.

\section{PENGUJIAN}

Metode Blackbox Testing digunakan untuk menguji validitas aplikasi ini dengan tujuan untukmengarahkan pada keperluan fungsional dari aplikasi.

\begin{tabular}{|c|l|c|}
\hline Aksi User & \multicolumn{1}{|c|}{ Reaksi Sistem } & Hasil Pengujian \\
\hline Menekan Form Pengaturan & $\begin{array}{l}\text { Memanggil halaman pengaturan } \\
\text { dimana pengguna melakukan } \\
\text { pengaturan aplikasi. }\end{array}$ & Sesuai \\
\hline
\end{tabular}

Hasil pengujian fungsional form pengaturan menunjukkan ketika pengguna melakukan proses pengaturan, reaksi sistem yang ditunjukkan adalah menampilkan halaman pengaturan dimana pengguna dapat melakukan pengaturan fungsi-fungsi dari aplikasi dan menyimpan konfigurasi pengaturan tersebut ke dalam sebuah file khusus. Berdasarkan hal tersebut maka dapat dikatakan bahwa hasil pengujian form pengaturan adalah sesuai.

\begin{tabular}{|c|l|c|}
\hline Aksi User & \multicolumn{1}{|c|}{ Reaksi Sistem } & Hasil Pengujian \\
\hline Menekan Form Utama & $\begin{array}{l}\text { 1. Memanggil halaman utama } \\
\text { dimana halaman website } \\
\text { ditampilkan. }\end{array}$ & Sesuai \\
& $\begin{array}{l}\text { 2. Mengunci desktop dan } \\
\text { beberapa fungsi umum MS } \\
\text { Windows. }\end{array}$ & \\
\hline
\end{tabular}

Hasil pengujian fungsional formutama menunjukkan ketika pengguna melakukan proses utama, reaksi sistem yang ditunjukkan adalah menampilkan halaman utama dimana halaman website yang alamatnya telah ditentukan ditampilkan dengan syarat komputer terhubung dengan jaringan internet. Berdasarkan hal tersebut maka dapat dikatakan bahwa hasil pengujian form utama adalah sesuai.

\begin{tabular}{|l|l|c|}
\hline \multicolumn{1}{|c|}{ Aksi User } & \multicolumn{1}{|c|}{ Reaksi Sistem } & Hasil Pengujian \\
\hline $\begin{array}{l}\text { Menekan Form Navigasi } \\
\text { Halaman }\end{array}$ & $\begin{array}{l}\text { Memanggil halaman berdasarkan } \\
\text { navigasi yang dipilih. }\end{array}$ & Sesuai \\
\hline
\end{tabular}

Hasil pengujian fungsional formnavigasi menunjukkan ketika pengguna melakukan proses navigasi, reaksi sistem yang ditunjukkan adalah menampilkan halaman website sesuai navigasi yang ditentukan. Berdasarkan hal tersebut maka dapat dikatakan bahwa hasil pengujian form navigasi adalah sesuai. 


\begin{tabular}{|c|l|c|}
\hline Aksi User & \multicolumn{1}{|c|}{ Reaksi Sistem } & Hasil Pengujian \\
\hline Menekan Form Keluar & $\begin{array}{l}\text { Memanggil haman } \\
\text { passworduntuk diisi pengguna, } \\
\text { dimana jika password sesuai } \\
\text { maka aplikasi akan keluar. }\end{array}$ & Sesuai \\
\hline
\end{tabular}

Hasil pengujian fungsional formkeluar menunjukkan ketika pengguna melakukan proses keluar, reaksi sistem yang ditunjukkan adalah menampilkan form password yang harus diisi oleh pengguna. Jika password sesuai maka aplikasi akan tertutup, dan sebaliknya jika password tidak sesuai maka aplikasi tidak akan tertutup. Berdasarkan hal tersebut maka dapat dikatakan bahwa hasil pengujian form keluar adalah sesuai.

\section{KESIMPULAN}

Berdasarkan hasil perancangan aplikasi maka jika aplikasi ini dibangundapat disimpulkan beberapa hal sebagai berikut:

a. Komputer yang digunakan untuk perpustakaan online dapat tidak dengan mudah diubah setingnya.

b. Pengguna tidak dapat membuka alamat website selain perpustakaan online BPS.

c. Halaman website yang telah ditentukan akan tampil pada web browser yang khusus dipasang pada aplikasi.

d. Pengguna tidak dapat membuka file-file yang tidak dijinkan.

\section{SARAN}

Berdasarkan perancangan yang telah dilakukan, maka saran yang dapat disampaikanadalah membangun aplikasi ini sehingga dapat dipasang pada komputer-komputer di perpustakaan BPS Provinsi Jawa Barat yang digunakan untuk mengakses perpustakaan online BPS. Agar aplikasi dapat berfungsi lebih banyak lagi, maka pengembangan lebih lanjut dapat dilakukan terutama untuk mengakomodir alamat website yang lebih dari satu.

\section{DAFTAR PUSTAKA}

BPS. (2018, 12 13). Pusat Pelayanan. Retrieved from Badan Pusat Statistik Provinsi Jawa Barat: https://jabar.bps.go.id/menu/3/pusat-pelayanan.html

Februariyanti, H., \& Zuliarso, E. (2012). Rancang Bangun Sistem Perpustakaan untuk Jurnal Elektronik. Dinamik, 1

Supriyanto, W., \& Muhsin, A. (2008). Teknologi Informasi Perpustakaan. Yogyakarta: Kanisius.

Webkit. (2018, 12 13). The WebKit Open Source Project. Retrieved from Webkit: https://webkit.org/project/ Yazdi, M. (2012). E-Learning Sebagai Media Pembelajaran Interaktif Berbasis Teknologi Informasi. Jurnal Ilmiah Foristek, 148. 